\title{
Organização dos Conselhos Municipais: governança e participação da sociedade civil
}

\section{Organization of Municipal Councils: governance and civil society participation

\author{
Organisation des Conseils Municipaux: gouvernance et la société civile \\ participation
}

Organización de los Ayuntamientos: gobierno y la sociedad civil

\author{
Michelle Muniz Bronstein* \\ Joaquim Rubens Fontes Filho** \\ Gabriel Alves Pimenta**
}

Recebido em 31/05/2016; revisado e aprovado em 06/10/2016; aceito em 31/10/2016

DOI: http:/ / dx.doi.org/10.20435/1984-042X-2017-v.18-n.1(07)

\begin{abstract}
Resumo: Este estudo se baseia na premissa de que as características formais que dão origem aos $\mathrm{CMs}$, somadas a uma estrutura de governança adequada, poderiam reforçar não apenas a participação, mas o aumento da confiança da sociedade civil na administração pública e uma maior eficiência na formulação de políticas. O que se pode evidenciar, ainda que com uma amostra limitada a quatro casos, é o quanto os CMs ainda devem avançar para se tornarem um instrumento efetivo de promoção da participação da sociedade civil.
\end{abstract}

Palavras-chave: conselhos municipais; governança; representação.

Abstract: This study is based on the premise that the formal characteristics that give rise to CMs added to an appropriate governance structure could enhance not only participation, but the increased confidence of civil society in public administration and greater efficiency in policy formulation. What may show, albeit with a limited sample of the four cases is how the CMs should also advance to become an effective instrument for promoting civil society participation.

Key words: municipal councils; governance; acting .

Résumé: Cette étude est basée sur la prémisse que les caractéristiques formelles qui donnent lieu à CMs ajoutés à une structure de gouvernance appropriée pourrait améliorer non seulement la participation, mais la confiance accrue de la société civile dans l'administration publique et une plus grande efficacité dans la formulation des politiques. Ce qui peut montrer, mais avec un échantillon limité à quatre cas était de savoir comment le CMs devrait également progresser pour devenir un instrument efficace de promotion de la participation de la société civile.

Mots-clés: conseils municipaux; gouvernance; représentation .

Resumen: Este estudio se basa en la premisa de que las características formales que dan lugar a los $\mathrm{CM}$ añaden a una estructura de gobierno adecuada podría mejorar no sólo la participación, pero el aumento de la confianza de la sociedad civil en la gestión pública y una mayor eficiencia en la formulación de políticas. Lo que puede mostrar, aunque con una muestra limitada a cuatro casos fue como el FC también debe avanzar para convertirse en un instrumento eficaz para promover la participación de la sociedad civil.

Palabras clave: consejos municipales; gobernabilidad; representación.

\section{INTRODUÇÃO}

Este trabalho busca compreender como se configura a participação da sociedade civil na administração pública, tendo como referência a atuação dos conselhos municipais (CM). Os CMs são estruturas assessórias integrantes do aparelho do Estado brasileiro, vinculados à gestão pública dos municípios, estabelecidos pela Constituição Federal brasileira de 1988 como forma de ampliar a participação dos

\footnotetext{
* Universidade do Grande Rio, Duque de Caxias, Rio de Janeiro, Brasil.

** Fundação Getúlio Vargas, Rio de Janeiro, Rio de Janeiro, Brasil.
} 
cidadãos na elaboração e implementação das políticas públicas, contribuindo dessa forma para fortalecer uma democracia participativa e aumentar a confiança na administração pública. A organização do CM é estabelecida com base na representação popular (COELHO; NOBRE, 2004) e da sociedade civil organizada (DE ALMEIDA VILELA, 2005), entendidas como ambientes mais abertos à participação, influência e controle do cidadão sobre a atuação do Estado.

Em consequência, uma adequada estrutura de governança dos conselhos deve ser capaz de estimular a participação dos cidadãos, direta ou indiretamente, o que por sua vez deverá promover a confiança da sociedade civil na administração pública. Entende-se por governança nesse contexto a adoção de regras claras de deliberação, processos transparentes e democráticos, accountability, controle externo efetivo, equidade de direitos de participação dos membros e dos cidadãos, capacidade de refletir e discutir os problemas da sociedade, não retringindo o debate a um grupo de atores influentes ou do governo.

É importante ressaltar que essa definição de governança abarca o conceito de participação, focado na organização de espaços que estimula uma inclusão de grupos anteriormente excluídos do processo democrático e, consequentemente, incrementam os mecanismos de controle de instituições e recursos, como apresentado por Wolfe e Stiffel (1994) e retomado por Jacobi (2002) e Tavares (2014). No entanto, como analisa Hodgson (2004), a mera existência dessas instâncias associativas não significa necessariamente uma participação adequada da sociedade no governo, mas eventualmente um modelo próximo de uma subcontratação ou, como denominou, uma configuração de "manufactured civil society" (HODGSON, 2004).

Para compreender a lógica da participação dos cidadãos nos CMs, e de que forma essa estrutura é capaz de interagir ou influenciar a administração pública, foi realizado estudo em quatro CMs - Saúde, Meio Ambiente, Cidade e Agricultura - que funcionam em Teresópolis, uma cidade de médio porte no interior do estado do Rio de Janeiro, Brasil. O artigo analisa como estão estruturadas as funções de governança dos CM e em que medida o cidadão consegue ter voz ativa nas deliberações dos CMs e influenciar na formulação das políticas públicas.

O trabalho está estruturado em cinco seções, sendo esta introdução a primeira. A segunda seção apresenta o contexto dos conselhos municipais e sua atuação no Brasil, seguido pelo referencial teórico que serviu de base para a investigação, compreendendo a discussão das teorias sobre participação da sociedade civil, conselhos, confiança da sociedade no estado, e governança pública. A seguir, é apresentada a metodologia do estudo, a definição das categorias de análise, e os casos observados são apresentados e discutidos. $\mathrm{O}$ artigo conclui com uma discussão sobre a capacidade da governança e atuação desses CMs em fomentar uma adequada participação, e trazendo propostas para desenvolvimento de estudos futuros.

\section{CONSELHOS MUNICIPAIS NO BRASIL COMO FORMA DE PARTICIPAÇÃO E ORGANIZAÇÃO POLÍTICA}

A administração pública brasileira possui basicamente dois mecanismos de participação, que operam em diversas áreas e níveis (BULHÕES, 2002; CARVALHO, 1998; CORTES, 2005; 1996; 1995; DAGNINO, 2002; RAICHELIS, 2000; SANTOS JUNIOR, 2001; TATAGIBA, 2002). O primeiro, os conselhos de políticas públicas, abrange áreas como saúde, trabalho e emprego, assistência social, desenvolvimento rural, educação, meio ambiente, planejamento e gestão urbana, entorpecentes, direitos da criança e do adolescente, do negro, da mulher, dos portadores de deficiências, do idoso. $\mathrm{O}$ segundo mecanismo é o orçamento par- 
ticipativo, realizado por diversas administrações municipais. Apesar de serem ainda pouco estudados (CORTES, 2005), os conselhos municipais de políticas públicas brasileiros têm sido considerados como "fóruns institucionalizados, similares aos encontrados na Inglaterra, Itália, Estados Unidos ou Canadá" (CORTES, 1996). Segundo Ronconi et al. (2011), os conselhos no Brasil podem ser divididos em três tipos principais, apesar de nem todos possuírem caráter deliberativo ou amparo em legislação federal: os conselhos de programas, os conselhos temáticos e os conselhos de políticas. No que diz respeito à área de atuação, de acordo com Lüchmann (2007), essas instâncias podem ser articuladas com as esferas locais, estaduais e federais e, no que se refere ao poder de decisão, podem ser deliberativos, consultivos e de assessoria.

De acordo com a Constituição Federal de 1988 (BRASIL, 1988) e das respectivas Emendas Constitucionais (BRASIL 2000a; BRASIL 2000b), essas instâncias de participação devem abranger trabalhadores, aposentados, empregadores, comunidade, sociedade civil e usuários em órgãos gestores e consultivos em diversas áreas da seguridade social e na gestão do Fundo de Combate e Erradicação da Pobreza (CORTES, 2005). Nessas instâncias, a regulamentação do modo de funcionamento de mecanismos e de ambientes participativos ocorre não apenas via legislação complementar e disposições constitucionais, mas também pela normatização produzida pelos organismos federais responsáveis pela implementação de políticas públicas.

Conforme Pinheiro (1996), há 20 anos havia cerca de 30 conselhos nacionais, deliberativos ou não, distribuídos em 10 áreas de atuação - trabalho, educação, assistência social, previdência social, defesa de direitos, cultura, saúde, ciência e tecnologia, meio ambiente e turismo sendo comum a existência de um modelo plural de governança, consubstanciado na participação de membros do governo, representantes de empresários, representantes dos trabalhadores e das associações da sociedade civil organizada.

Diretamente envolvidos nos processos decisórios sobre bens e serviços públicos, os conselhos participam das decisões sobre políticas públicas na medida em que a transferência de recursos financeiros da esfera federal para as subnacionais de governo tem sido condicionada à criação de fóruns de participação em nível federal, estadual e municipal da administração pública. Assim, para que o município esteja habilitado a receber recursos financeiros específicos oriundos da esfera federal, é necessária a criação de conselhos organizados de acordo com as determinações legais - federais, estaduais e municipais - bem como das regulamentações administrativas.

Nesse sentido, considerando que a maior parte dos conselhos tem atribuições relativas ao planejamento e fiscalização da aplicação de recursos financeiros, transferidos da esfera de governo federal ou estadual, e relacionadas ao monitoramento da implementação de políticas, o estudo da governança dessas esferas, ponto que será tratado a seguir, torna-se fundamental para a questão da confiança. É necessário, portanto, refletir se a adoção de regras claras, de processos transparentes, democráticos, de accountability, de um controle externo efetivo, contribuem de fato para uma participação mais efetiva e legítima com equidade de direitos de participação dos membros e com a capacidade de espelhar e discutir os problemas da sociedade (e não de um grupo de atores influentes ou do governo).

\section{O QUE OS AUTORES DIZEM A RESPEITO DA GOVERNANÇA, SOCIEDADE CIVIL E MANUFACTURED CIVIL SOCIETY}

Nesta seção, são apresentados alguns dos conceitos fundamentais a respeito da Governança, sociedade civil e manufactured civil society. Esta apresentação tem 
a intenção de situar o leitor sobre o ponto de partida das discussões levantadas e o modo como os autores buscam articular os conceitos envolvidos a respeito da governança e sua aplicação no cenário da administração pública.

Ao aplicar o referencial que trata da governança para entendimento dos processos de estruturação e funcionamento dos CMs, a ideia de participação da sociedade civil é problematizada. Discutese a participação como indutora de boas práticas de governança e de processos de acompanhamento e controle mais efetivos e legítimos e como reprodutora da situação classificada pela literatura como Manufactured Civil Society.

O termo governança origina-se do latim "gubernare", traduzido por "governar", "dirigir", "guiar", recuperado no setor privado para conceituar o sistema pelo qual os acionistas de uma empresa ("corporation") "governam", ou seja, encarregam-se de sua empresa (SERAFIM; QUELHAS, 2010, p. 3). Os problemas de governança das empresas foram apontados, inicialmente, por Adolf Berle e Gardiner Means, em 1932, ao observarem o comportamento dos administradores de empresas de capital aberto. Em virtude da separação entre a propriedade da empresa e o controle de suas atividades, esses administradores poderiam privilegiar práticas e ações que lhes traziam benefícios pessoais, e não riqueza para os acionistas (FONTES FILHO, 2003). Mais recentemente, as discussões de governança têm avançado para inúmeros outros campos (KOOIMAN,1999), em especial sobre a administração pública, como denotam as preocupações recentes expressas nas orientações do Tribunal de Contas da União (TCU, 2014).

Trazendo a ideia de governança para o âmbito dos CMs pressupõe-se que este fenômeno está relacionado à capacidade de os conselheiros conseguirem pactuar normas claras, processos transparentes e democráticos, com accountability e contro- le externo efetivo para produzirem, nessas instâncias de participação, um conjunto de boas práticas que levem ao aumento da confiança dos cidadãos na gestão pública. Para organizações dos setores público ou não empresariais, boas práticas de governança contribuem para institucionalizar as estruturas e dinâmicas decisórias das organizações, ampliando sua transparência e facilitand o o controle externo - o que pode contribuir para a confiança. Com isso, é possível que o próprio sistema crie mecanismos de fiscalização entre suas organizações, melhorando a segurança e a imagem de todos, principalmente em setores que estão menos sujeitos à fiscalização e controle dos agentes de mercado (FONTES FILHO, 2013).

No entanto, é preciso ponderar se a participação da sociedade civil nos CMs favorece a adoção de boas práticas de governança - o que inclui a transparência nos processos decisórios; a equidade de direitos entre os participantes; a prestação de contas responsável e a conformidade com os parâmetros regulatórios que instituem e mantêm esses conselhos. Em outras palavras, é preciso fazer a ressalva a respeito dessa participação na dinâmica dos CMs, se é realmente capaz de contribuir para uma atuação mais efetiva e legítima, resultando na equidade de direitos de seus membros que passam a ter capacidade de espelhar e discutir os problemas da sociedade (e não de um grupo de atores influenciados ou direcionados unicamente pelo governo).

Para investigar essa situação, duas ideias fundamentais são consideradas na orientação dos instrumentos da pesquisa: o conceito, em sua abrangência e delimitação, de sociedade civil (organizada), e a concepção da manufactured civil society, discutidos na seção seguinte.

A ideia de sociedade civil remete ao ambiente em que indivíduos se organizam livre e voluntariamente a partir de interesses comuns, formando grupos e associações (DEAKIN, 2001; WALZER, 1995). 
Por sua vez, o conceito de "sociedade civil organizada", utilizado por vezes sem uma adequada definição, é tratado neste texto como proposto por Viana (2003, p. 29), como "uma mediação burocrática entre sociedade civil e estado". Essa condição o distingue da ação individual do cidadão, e inclui a atuação organizada no âmbito de organizações como cooperativas, associações profissionais, corporações de classe, grupos ambientais e de advocacy em geral, instituições de benemerência, entre outros.

Falanga (2013) analisa que formas de participação democráticas assumidas dentro de sistemas políticos promovem a legitimidade e o engrandecimento ao envolver os cidadãos, tanto quanto facilita o entendimento sobre qual escolha pública está sendo feita, e quais são as medidas que asseguram a igualdade política. Contudo existem elementos questionáveis nessa relação principalmente quanto a compreensão social dos processos decisórios e equidade das políticas. Dentre esses elementos, destaca-se o "Manufactured Civil Society" analisado por Hodgson (2004).

Segundo Hodgson (2004), a ideia do Manufactured Civil Society se refere a grupos formados e financiados, pelo menos em sua fase inicial, por algum tipo de iniciativa estatal. Esses grupos, dada sua natureza e fonte de recursos, precisam prestar contas ao Estado sobre suas ações e finanças e, via de regra, atender a critérios e metas fixados pelo governo. Apesar de serem parte de um programa nacional, tais grupos atuam diretamente nas comunidades. Entretanto, em função do papel do Estado em sua criação e funcionamento, esses grupos podem ser percebidos mais como ambientes de legitimação das suas ações, do que como ambiente de participação popular e democrática. Tais grupos podem se tornar extensões do governo, de certa forma disfarçados, no momento em que atuam segundo uma orientação de valores intrín- secos que visam à transmissão de certas habilidades, e a concordância ou aceitação dos indivíduos com as ações do governo (HODGSON, 2004).

Essa condição pode estar presente também nos CMs, à semelhança do observado por Hodgson (2004) no contexto inglês - uma vez que as características de estruturação e funcionamento dessas instâncias, no Brasil, podem produzir a percepção na sociedade dos CMs enquanto uma extensão do governo municipal sob o disfarce de sociedade civil. Como analisa o autor, a mera existência dessas instâncias associativas não significa necessariamente uma participação adequada da sociedade no governo, mas eventualmente um modelo próximo de uma subcontratação ou, como denominou, uma configuração de manufactured civil society (HODGSON, 2004).

Segundo Cortes (2005), a criação de instâncias de participação como os CMs não é garantia de uma participação efetiva e de envolvimento nas decisões políticas que ocorrem em determinada área da administração pública. Isso porque os membros do conselho que fazem parte da sociedade civil (em sua maioria representantes de movimentos sociais, populares, sindicais e de grupos de interesses de usuários) podem escolher não se envolver, ou seu envolvimento pode redundar em manipulação, consulta ou somente no acesso a informações (ARNSTEIN, 1969; CHOGUILL, 1996; PAUL, 1987).

De fato, evidências de ocorrência dessa percepção de uma "sociedade civil manufaturada", envolvendo as relações do Estado brasileiro com a sociedade, já foram identificadas no país. Analisando o contexto do denominado Choque de Gestão conduzido no estado de Minas Gerais, ao longo da primeira década de 2000 e início da década seguinte, Peci, Figale e Sobral (2011) observaram que os contratos de parcerias entre o governo e organizações da sociedade civil de interesse público (OSCIP) exibiam 
a centralidade do governo e seu papel técnico-burocrático na promoção e orientação dos projetos desenvolvidos pelas OSCIPs, evidenciado na escolha e uso de indicadores de desempenho, critérios, funding, auditorias e controles, além de uma "invasão" de valores de mercado e narrativas governamentais.

Outro ponto a ser ressaltado sobre a manufactured civil society é quanto ao perfil dos participantes nos conselhos. Em um estudo feito nos conselhos gestores do Paraná, Fuks, Perissinotto e Souza (2004) apresentam a conclusão de que o formato adotado por esses conselhos no Brasil impulsiona-lhes a elitização. Este estudo demonstra que há uma certa homogeneização dos participantes, que, apesar de representarem organizações diversas, são oriundos de uma parcela da população com renda, escolaridade e engajamento político mais elevados que as médias nacionais, e muitos são membros do funcionalismo público, o que fundamentalmente limita a representatividade dos conselhos gestores.

Dessa forma, questiona-se o argumento de que a participação popular na gestão pública configurada nos CMs está associada a um melhor atendimento às necessidades e interesses da população, segundo a premissa de que a proliferação desses Conselhos é um fenômeno positivo por criar oportunidades para a participação da sociedade na administração pública e gerar confiança na seleção, configuração e implantação das políticas públicas.

\section{METODOLOGIA E MODELO DE ANÁLISE}

A investigação foi baseada no estudo de caso, comuns em estudos de natureza qualitativa em ciências sociais aplicadas (COELHO CESAR, 2006), em quatro CMs - Saúde, Meio Ambiente, Cidade e Agricultura - em operação no município fluminense de Teresópolis, cidade serrana de 160 mil habitantes e próxima à capital estadual. A escolha desse município se deu em razão da facilidade de acesso às assembleias assim como aos entrevistados. Somam-se a essa razão o fato de a cidade ter sofrido, há cerca de cinco anos, a maior tragédia natural do Brasil, deixando 918 mortos e cerca de 30 mil desalojados e desabrigados (SCARINI; RODRIGUES, 2016), e ainda, a complicada cena política que se encontra. Em pouco mais de três anos, o município foi governado por três prefeitos, dois deles sendo afastados diversas vezes por má administração de recursos públicos (SCARINI, 2016).

Para cada CM, foi construído material de análise coletado por meio de participações presenciais nas assembleias realizadas nos meses de fevereiro e março de 2015, de entrevistas longas com os presidentes de cada conselho e de informações disponíveis nos estatutos. Ao todo se assistiu a oito reuniões, sendo duas de cada conselho, e foram realizadas quatro entrevistas com aproximadamente 1 h30 cada uma. Na ocasião das reuniões a que se assistiu, não houve problema de quórum. Os presidentes foram escolhidos como informantes qualificados para entrevista, tendo em vista que, por ocuparem uma posição estratégica na esfera decisória dos CMs, ao fim e ao cabo são os responsáveis pelas medidas que irão favorecer/dificultar a participação dos membros da sociedade civil que fazem parte desses Conselhos, e pela articulação de propostas e recomendações aprovadas em assembleias nas demais instâncias do governo municipal.

A entrevista longa, de acordo com Grant McCracken (1988), ocupa um lugar especial no conjunto das metodologias qualitativas e se mostra bastante eficiente e pouco obstrutiva. A técnica de observação nas ciências sociais permite perceber $\mathrm{O}$ fato no local em que este acontece, ou seja, no seu ambiente natural (ANGROSINO; PEREZ, 2000). A escolha desses conselhos levou em conta que, além de estarem 
constituídos formalmente e regulamentados pelo Poder Público, compartilham valores semelhantes associados à vida, ao bem-estar social, ao desenvolvimento econômico rural e urbano e à sustentabilidade.
Para a execução da pesquisa foram construídas quatro categorias de análise, com base na discussão teórica anterior (Quadro 1), a partir das quais foram elencados os tópicos que compuseram o roteiro de entrevistas.

\begin{tabular}{|c|l|}
\hline CATEGORIA & \multicolumn{1}{|c|}{ DEFINIÇÃO (CONSTITUTIVA/OPERACIONAL) } \\
\hline $\begin{array}{c}\text { Participação e } \\
\text { composição }\end{array}$ & $\begin{array}{l}\text { Quem pode participar do CM e qual é a forma de composição (número de } \\
\text { membros do poder público/sociedade civil) }\end{array}$ \\
\hline Funcionamento & $\begin{array}{l}\text { Inclui aspectos legais, estrutura de gestão (estrutura física; material; re- } \\
\text { cursos humanos), elaboração dos temas em pauta, processos assembleares } \\
\text { (onde se reúne; quando; quórum; quantas vezes; voto de minerva); }\end{array}$ \\
\hline Accountability & $\begin{array}{l}\text { Inclui formas de prestação de contas, acessibilidade à informação, formas } \\
\text { de divulgação dos resultados do trabalho; }\end{array}$ \\
\hline Confiança & $\begin{array}{l}\text { Influência da participação no CM versus confiança na administração pública } \\
\text { municipal }\end{array}$ \\
\hline
\end{tabular}

Quadro 1 - Categorias de análise

Fonte: Elaboração própria

Com base nessas categorias e definições, foram os seguintes os tópicos incluídos no roteiro de entrevista: Quem pode participar do CM; Forma de composição (número de membros do poder público/ sociedade civil); Normas de funcionamento; Elaboração dos temas em pauta; Formas de prestação de contas; Processos Assembleares (onde se reúne; quando; quórum; quantas vezes; voto de minerva); Estrutura de gestão (estrutura física; material; recursos humanos); Formas de divulgação dos resultados do trabalho; Como essa participação influencia sua confiança na relação/parceria com o estado, sua autonomia etc.

A partir das observações realizadas, foi produzida uma síntese dos casos e o material tratado com base nas técnicas de análise de conteúdo, anotando principais semelhanças e diferenças, seguida de uma avaliação distribuída segundo as categorias de análise previamente definidas.

\section{SÍNTESE DOS CASOS}

O CM de Saúde de Teresópolis (CMST) é o mais antigo dos quatro conselhos estudados. Criado no ano de 1990, é um órgão colegiado de caráter permanente de natureza representativa e participativa, instituído como mecanismo de articulação do poder executivo municipal, da sociedade civil organizada e da população em geral. Possui, de acordo com seu regimento interno, funções consultivas, deliberativas e fiscalizadoras na área específica da saúde "exercidas com autonomia e independência de qualquer influência ou pressão externa" (CMST, 2009). Sua composição é paritária, formada por representantes do poder público e da sociedade civil organizada, tais como de Associações de Moradores, entidades privadas sem fins lucrativos que prestam serviços na área da saúde, sindicatos etc. OCMST possui 32 membros com mandato de dois anos.

O CM de Defesa do Meio Ambiente de Teresópolis (CONDEMA) foi criado em 2008, e é, por definição estatutária, um 
órgão deliberativo vinculado ao Gabinete do Prefeito. Entre suas principais atribuições, estão o assessoramento do Prefeito no que diz respeito à formulação das diretrizes da política municipal de meio ambiente; o acompanhamento da execução do Fundo do Meio Ambiente e a elaboração de normas técnicas e procedimentos voltados para o planejamento e a execução de programas de proteção ambiental. Do mesmo modo como acontece com CMST, a composição do CONDEMA é paritária, formada por 24 membros com mandato de dois anos, representantes do poder público e da sociedade civil organizada.

Também de modo bastante similar ao CMST, o Conselho Municipal da Cidade e Desenvolvimento Sustentável de Teresópolis (CMCDS) é um órgão colegiado de caráter permanente, de natureza representativa e participativa, instituído como mecanismo de articulação do Poder Executivo Municipal, da sociedade civil organizada legalmente constituída (com poder de voz e voto em reuniões ordinárias e extraordinárias) e da população em geral (limitada ao poder de voz nas reuniões), com funções consultivas, deliberativas e fiscalizadoras, atuando como instância de controle social, nas áreas do desenvolvimento urbano, rural e sustentável, exercidas com autonomia e independência de qualquer influência ou pressão externa (CMCDS, 2008). Diferentemente do que ocorre nos demais CMs, no CMCDS a composição não é paritária. Esse conselho possui 21 membros, sendo 12 da sociedade civil organizada e nove do poder público municipal, todos com mandato de dois anos.

O CM de Agricultura, denominado Conselho Municipal de Desenvolvimento Rural Sustentável de Teresópolis (CMDRST), foi criado em 1998. Segundo seu estatuto, é um órgão consultivo e deliberativo, vinculado ao gabinete do Prefeito e composto por representantes do poder público e da sociedade civil organizada, tais como presidentes de
Associações de Moradores, de cooperativas de produção e sindicatos rurais. Entre suas principais atribuições, estão o assessoramento do prefeito no que diz respeito à formulação das diretrizes relacionadas à política municipal de agricultura e extensão rural, bem como e a elaboração de normas técnicas e procedimentos voltados para o planejamento e a execução de programas que visem ao desenvolvimento rural de forma sustentável. Sua composição é, também, com 20 membros com dois anos de mandato.

Apesar de a estrutura formal de criação ser comum a todos os casos estudados, a motivação de criação de cada conselho é diferente. O CMST está inserido dentro do sistema nacional de saúde que estabeleceu sua criação e diretrizes de funcionamento na década de 1990 em decorrência da criação do Sistema Único de Saúde (SUS). O CMST é regulamentado pela Lei Orgânica da Saúde e pelo Conselho Nacional da Saúde.

O CONDEMA é uma estrutura administrativa peculiar à gestão ambiental no Brasil sendo criado como uma representação em nível local do que ocorre em nível nacional como o Conselho Nacional de Meio Ambiente (CONAMA), fundamentado no artigo 20 da resolução n. 237/97 do CONAMA e no princípio da participação popular integrante do direito ambiental brasileiro. O CMCDS foi criado pela Lei Municipal n. 2.597 de 3 de outubro de 2007, pela qual é regido, junto com as outras leis e normas competentes que regulam o funcionamento dos conselhos dessa natureza. Sua origem decorre da criação do Ministério das Cidades em 2003 com os objetivos de combater as desigualdades sociais, transformar as cidades em espaços mais humanizados e ampliar o acesso da população a moradia, saneamento e transporte.

No caso do CMDRST, a motivação se deu a partir da criação do Programa Nacional de Fortalecimento da Agricultura Familiar (PRONAF) - um 
programa do governo federal criado em 1996 com os objetivos de atender, de forma diferenciada, os mini e pequenos produtores rurais; possibilitar a elevação de sua capacidade produtiva; gerar emprego e renda; contribuir para a redução das desigualdades sociais (BRASIL, 1996).

\subsection{Avaliação por cada categoria de análise}

Relacionando as categorias de análise com as metodologias empregadas, foi observado que as categorias: "Participação e composição" e "Funcionamento" possuíram uma melhor avaliação através do estudo das informações disponíveis nos estatutos. Já as categorias Accountability e Confiança, obtiveram um melhor resultado de avaliação a partir das entrevistas e da observação das reuniões, visto que os estatutos são constituídos pelo regulamento, ou seja, pelo conjunto de regras dos Conselhos que disciplinam as relações jurídicas que afetam seu funcionamento e a participação de seus membros. A avaliação por cada categoria de análise diz respeito ao conjunto dos casos estudados.

\section{(a) Participação e composição}

De acordo com informações obtidas nos estatutos, confirmadas nas entrevistas realizadas com os presidentes de cada CM e na observação das assembleias ordinárias, a composição dessas instâncias de participação é feita com representantes legalmente e formalmente constituídos da sociedade civil organizada, ou seja, para obter assento em cada um desses conselhos, o cidadão comum deve se tornar representante legal de alguma entidade (associação de moradores, organização não governamental, empresa, sindicato etc.). Muito embora as reuniões sejam públicas, o cidadão comum somente tem direito à voz, sem voto, este restrito aos membros formais dos CMs. Os membros dos CMs que ocupam as vagas destinadas à sociedade civil organizada são aqueles eleitos pelos pares dentro das comuni- dades e/ou instituições das quais fazem parte como seus representantes legítimos.

\section{(b) Funcionamento}

Por serem instâncias vinculadas ao poder público municipal, com funções de assessoramento ao executivo principal do município, esses conselhos são formalmente criados por meio de decretos municipais sancionados na Câmara dos Vereadores. A formalização dessas instâncias se dá a partir do decreto de criação por meio de regimentos internos. A gestão dos CMs funciona dentro dos ambientes da Prefeitura Municipal.

A estrutura administrativa a partir da qual se operam as atividades dos CMs são cedidas pela Prefeitura, assim como os funcionários que atendem as demandas de ordem operacional e de comunicação. Essa estrutura de suporte viabiliza o funcionamento dos Conselhos e, sob certos aspectos, faz com que os membros dos CMs considerem que essas instâncias de participação representem uma extensão da Prefeitura. Os temas em pauta são definidos durante as assembleias ordinárias e também por contatos mais eventuais de conselheiros junto à presidência, que decide incluir, ou não, certo ponto de pauta.

À exceção do CMST, os presidentes dos CMs são estatutariamente os mesmos indivíduos que ocupam os cargos de Secretários Municipais das respectivas pastas - o que pode levar ao risco de conflito de interesses em razão de sobreposição de funções. De acordo com dados colhidos em entrevistas, essa sobreposição tem causado certo desconforto nos presidentes/secretários durante as reuniões em função da ambiguidade nos papéis desempenhados, motivo que tem levado os CMs a proporem mudanças estatutárias e alterações nos regimentos internos para que o Secretário da pasta ocupe o lugar de vice-presidente e que a vaga de presidente seja ocupada por um representante da sociedade civil organizada. Assim como a estrutura administrativa, a estrutura 
física para a realização das assembleias ordinárias mensais é da Prefeitura.

O quórum estabelecido em todos os casos estudados obedece ao critério e pelo menos $50 \%$ dos membros em primeira convocação, sendo relatado pelos presidentes, com exceção do Conselho de Saúde, a dificuldade de se obter quórum nas reuniões. Em caso de empate nas votações, o presidente de cada $\mathrm{CM}$ possui voto de minerva.

\section{(c) Accontability}

No que diz respeito às formas de prestação de contas, acessibilidade à informação, formas de divulgação dos resultados do trabalho, observou-se nas falas dos entrevistados, observação em reuniões e nos poucos documentos institucionais disponíveis para consulta, que as contas de cada CM, principalmente quando gestores de Fundos Municipais, são não apenas controladas internamente pelos seus membros conselheiros, como também conciliadas dentro da contabilidade da Prefeitura e auditadas pelo Ministério Público.

Além dessa característica referente à formalização da prestação de contas nos aspectos contábeis-financeiros, há que se considerar como objeto de análise, sob a transparência dessas instâncias, as comunicações dos atos, resoluções, pautas, estudos e atas de reuniões para os cidadãos de uma forma geral, independentemente de serem membros dos CMs ou não. À exceção do CM de Meio Ambiente que, segundo seu presidente, tem reunido esforços para tornar públicos e acessíveis via internet as informações geradas dentro do conselho, os demais presidentes informaram que o acesso à informação é aberto a qualquer cidadão que compareça nas reuniões. Dito de outra forma, o cidadão comum que tiver interesse de se inteirar dos assuntos discutidos dentro de cada Conselho deve procurar comparecer nas assembleias ordinárias, muito embora a agenda de marcação do dia, horário e local de realização seja rotineiramente comunicada via e-mail somente aos membros de cada CM - o que, de certa forma pode dificultar o acesso à informação e ao acompanhamento da agenda pelo cidadão comum, assim como pode vir a dificultar a renovação desses Conselhos, diante do acesso restrito à informação sobre as reuniões.

Além dessa forma de acompanhamento in loco, essas estruturas associativas de participação também contam com a representatividade de seus membros enquanto mecanismo de divulgação, ou seja, cabe aos representantes das Associações, Organizações sem fins lucrativos (OSFLs), cooperativas, sindicatos etc. a transmissão dos conteúdos discutidos em cada CM aos demais membros da comunidade a qual representa.

\section{(d) Confiança}

A participação da sociedade civil organizada nos CMs não parece produzir impacto na confiança do cidadão comum na gestão pública municipal, conforme extraído da fala dos presidentes dos CMs e das observações das assembleias. Segundo relatado pelos presidentes e observado nas reuniões, as discussões e o conhecimento gerado sobre os problemas de cada comunidade nessas assembleias são, de certa forma, herméticos e restritos aos participantes desses fóruns, com poucas chances de alcançar o cidadão comum. Nesse sentido, seja pela dificuldade de acesso à informação, seja pela falta de interesse na participação, motivada pela pouca efetividade percebida na atuação do CM pela sociedade, os cidadãos têm poucas chances de participar efetivamente.

Ao que parece, a governança dos CMs estudados ainda carece de evolução. A partir dos resultados obtidos, o que se observa, do estudo do corpo regulatório dessas instâncias e das práticas informadas por seus presidentes, é que a adoção de boas práticas de governança e operação dos CMs, com regras claras, processos transparentes, democráticos, accountabi- 
lity, controle externo efetivo, equidade de direitos de participação dos membros, capacidade de refletir e discutir os problemas da sociedade (e não de um grupo de atores influentes ou do governo), podem vir a estimular uma maior participação e ampliar a confiança do cidadão na administração pública municipal. Entretanto o modelo atual ainda se mostra muito aquém do necessário para garantir uma participação e uma confiança efetiva.

\section{CONSIDERAÇÕES FINAIS}

Este artigo se desenvolveu com base na premissa de que as características formais que dão origem aos CMs no Brasil (aspectos regulatórios, fiscalizatórios e burocráticos) somadas a uma estrutura de governança adequada dessas instâncias, baseada na transparência e participação da sociedade, reforçaria não apenas essa participação - ampliando seu escopo e intensidade - mas ainda o aumento da confiança da sociedade civil na administração pública e uma maior eficiência na formulação de políticas. O que se pode evidenciar neste estudo, ainda que com uma amostra limitada a quatro casos, foi o quanto os CM ainda devem avançar para se consolidarem como um instrumento efetivo de promoção da participação da sociedade civil, organizada ou não, nos assuntos da administração pública que mais lhe afetam diretamente.

Considerando a definição utilizada proposta por Viana (2003) e por Wolfe e Stiffel (1994) para sociedade civil organizada e participação, há de fato um espaço de participação da sociedade nesses conselhos e principalmente a inclusão de participantes que anteriormente seriam deixados de lado.

Entretanto devemos avaliar a capacidade de essas instâncias "organizadas" representarem interesses legítimos de distintos grupos. Os CMs, como observados até o momento, se aproximam mais das denominadas meta-organizações que, conforme Ahrne e Brunsson (2011), possuem outras organizações como seus membros, do que de instâncias de participação direta, como intenciona a constituição de 1988, e descrevem autores como Cortes (2005) e Falanga (2013). A exemplo do que foi apresentado por Fuks, Perissinotto e Souza (2004) em que os conselheiros acabaram se tornando representantes elitizados de organizações, e até mesmo do próprio serviço público, os CMs podem, devido à estrutura frágil que apresentam, tornar-se fóruns limitados e pouco representativos de discussão entre organizações nos quais a participação direta do cidadão acaba desencorajada ou diluída.

Por certo que fazer do CM um mecanismo de participação direta pode criar inúmeros problemas adicionais para controlar a participação e, principalmente, a representatividade. No modelo de participação e na estrutura atualmente em vigor, restam questões que ainda carecem de solução que emergem principalmente do baixo incentivo à expansão da participação da sociedade na administração pública e da aparente baixa efetividade nessa participação. Em paralelo, a percepção dos CMs como órgãos da administração pública, e não como instrumentos da própria sociedade, pode representar uma barreira ao aprimoramento do relacionamento e da confiança entre essas partes e consequentemente limitar o ímpeto social de participação.

Muito ainda há que avançar nessa discussão. A escolha pelo estudo de caso neste trabalho permitiu uma melhor compreensão dentro de um escopo restrito, mas é provável que outras características, tais como o porte do município, sua natureza econômica, ou mesmo formação cultural, tragam distintas discussões sobre a governança e atuação desses conselhos. Novos trabalhos podem ampliar essas fronteiras nesse sentido. 


\section{REFERÊNCIAS}

AHRNE, G.; BRUNSSON, N. Metaorganizations. Cheltenham: Edward Elgar Publishing, 2011.

ANGROSINO, M. V.; MAYS DE PÉREZ, K. A. Rethinking observation: from method to context. In: DENZIN, N. K.; LINCOLN, Y. S. (Ed.). Handbook of Qualitative Research. 2. ed. Thousand Oaks: Sage, 2000. p. 673-702.

ARNSTEIN, S. R. A ladder of citizen participation. Journal of the American Institute of Planners, v. 35, n. 4, p. 216-224, 1969.

BRASIL. Emenda Constitucional n. 30, de 13 de setembro de 2000. Altera a redação do Art.100 da Constituição Federal e acrescenta o Art. 78 no Ato das Disposições Constitucionais Transitórias, referente ao pagamento de Precatórios Judiciais. Diário Oficial da União, Brasília, p. 2, Seção I, 14 set. 2000a.

Emenda Constitucional n. 31, de 14 de dezembro de 2000. Altera o ato das Disposições Constitucionais Transitórias, introduzindo artigos que criam o Fundo de Combate e Erradicação da Pobreza. Diário Oficial da União, Brasília, p.18, 18 dez. 2000b.

. Constituição da República Federativa do Brasil. 1988. Disponível em: <http://www. planalto.gov.br/ccivil_03/constituicao/ constituicao.htm>.

Decreto n. 1.946, de 28 de junho de 1996. Cria o Programa Nacional de Fortalecimento da Agricultura Familiar - PRONAF, e dá outras providências. Brasília, 1996.

BULHÕES, M. D. G. P. Plano Nacional de Qualificação do Trabalhador-Planfor: acertos, limites e desafios vistos do extremo sul. São Paulo em Perspectiva, v. 18, n. 4, p. 39-49, 2004.

CARVALHO, A. D. Os conselhos de saúde, participação social e reforma do Estado. Ciência E Saúde Coletiva, v. 3, n. 1, p. 23-25, 1998.

CHOGUILL, M. B. G. A ladder of community participation for underdeveloped countries. Habitat international, v. 20, n. 3, p. 431-444, 1996.

COELHO CESAR, A. M. R. V. Método do Estudo de Caso (Case Studies) ou Método do Caso (Teaching Cases)? Uma análise dos dois métodos no Ensino e Pesquisa em Administração. São Paulo: Universidade Presbiteriana Mackenzie, 2006. Disponível em: <http://www.mackenzie.br/fileadmin/ Graduacao/CCSA/remac/jul_dez_05/06. pdf>. Acesso em: 20 fev. 2014.

COELHO, V. S. P.; NOBRE, M. Participação e deliberação: teoria democrática e experiências institucionais no Brasil contemporâneo. São Paulo: Editora 34, 2004.

CONSELHO MUNICIPAL DA CIDADE E DESENVOLVIMENTO SUSTENTÁVEL DE TERESÓPOLIS (CMCDS). Regimento Interno. Teresópolis, RJ, 2008.

CONSELHO MUNICIPAL DE DESENVOLVIMENTO RURAL SUSTENTÁVEL DE TERESÓPOLIS (CMDRST). Regimento Interno. Teresópolis, RJ, 1998.

CONSELHO MUNICIPAL DE SAÚDE DE TERESÓPOLIS (CMST). Regimento Interno. Teresópolis, RJ, 2009.

CONSELHO NACIONAL DO MEIO AMBIENTE (CONAMA). Resolução n. 237, de 19 de dezembro de 1997, publicada no DOU em 22 de dezembro.

CONSELHO DE DEFESA DO MEIO AMBIENTEDETERESÓPOLIS(CONDEMA). Regimento Interno. Teresópolis, RJ, 2008.

CORTES, S. M. V. Arcabouço históricoinstitucional e a conformação de conselhos municipais de políticas públicas. Educar em Revista, Curitiba, n. 25, p. 143-174, 2005.

Fóruns participatórios na área de saúde: teorias do estado, participantes e modalidades de participação. Saúde em Debate, n. 49/50, p. 73-9, 1996.

. User participation and reform of the Brazilian health system: the case of Porto Alegre. 1995. Thesis (Doctoral in Philosophy) - University of London, 1995.

DAGNINO, E. Sociedade civil, espaços públicos e a construção democrática no Brasil: limites e possibilidades. In: DAGNINO, Evelina (Org.). Sociedade civil e espaços públicos no Brasil. São Paulo: Paz e Terra, 2002. p. 279301.

DEAKIN, N. In search of civil society. Basingstoke: Palgrave, 2001. 
DE ALMEIDA VILELA, M. D. Legislação que disciplina os conselhos de políticas públicas. Brasília: Câmara dos Deputados, mar. 2005. Disponível em: <http:/ /www2.camara.leg. $\mathrm{br} /$ documentos-e-pesquisa/publicacoes/ estnottec/areas-da-conle/tema6/2005_740. pdf $>$.

FALANGA, R. Participation and public sector: a democratic challenge. Universitas Humanas, Brasília, v. 10, n. 2, p. 11-20, jul./dez. 2013. Disponível em: "https://www.publicacoes. uniceub.br/universitashumanas/article/ view/2998/2435>.

FONTES FILHO, J. R. O que podemos aprender com a governança das organizações públicas e não empresariais. In: FONTES FILHO, Joaquim Rubens; LEAL, Ricardo Pereira Câmara (Org.). O futuro da governança corporativa: desafios e novas fronteiras. São Paulo: Saint Paul, 2013. Cap. 15, p. 263-284.

. Governança organizacional aplicada ao setor público. In:CONGRESO INTERNACIONAL DEL CLAD SOBRE LA REFORMA DEL ESTADO Y DE LA ADMINISTRACIÓN PÚBLICA, 8., Panamá, 2003. p. 28-31.

FUKS, M.; PERISSINOTTO, R. M.; SOUZA, N. R. (Org.). Democracia e participação: os conselhos gestores do Paraná. Curitiba: UFPR, 2004.

HODGSON, L. Manufactured civil society: counting the cost. Critical social policy, v. 24, n. 2, p. 139-164, 2004.

JACOBI, P. R. Políticas sociais e ampliação da cidadania. 2. ed. Rio de Janeiro: FGV, 2002.

KOOIMAN, J. Social-political governance: overview, reflections and design. Public Management: an international journal of research and theory, v. 1, n. 1, p. 67-92, 1999.

LÜCHMANN, L. H. H. A representação no interior das experiências de participação. Lua Nova, n. 70, p. 139-170, 2007.

MCCRACKEN, Grant D. The long interview. Califórnia: Sage, 1988. (Qualitative Research Methods, v. 13).

PAUL, S. Community participation in development projects. Washington, DC: World Bank, 1987.

PECI, A.; FIGALE, J.; SOBRAL, F. The "invasion" of manufactured civil society: government-nonprofit partnerships in a Brazilian state. Public Administration and Development, n. 31, p. 377-389, 2011.

PINHEIRO, R. I. A dinâmica dos conselhos municipais de saúde do estado do Rio de Janeiro: três estudos de caso (Angra dos Reis, Resende e Bom Jesus de Itabapoana). Revista da Administração Pública, Rio de Janeiro, v. 30, n. 5, p. 64-98, set./out. 1996.

RAICHELIS, R. Esfera pública e conselhos de assistência social: caminhos da construção democrática. São Paulo: Cortez, 1998.

RONCONI, L. F. D. A.; DEBETIR, E.; DE MATTIA, C. Conselhos Gestores de Políticas Públicas: potenciais espaços para a coprodução dos serviços públicos. Contabilidade, Gestão e Governança, Brasília, v. 14, n. 3, p. 46-59, set./ dez. 2011.

SANTOS JR., O. A. D. Democracia e governo local: dilemas da reforma municipal no Brasil. Rio de Janeiro: Revan/Fase, 2001.

SCARINI, J. Mário Tricano assume a Prefeitura de Teresópolis, no RJG1 Região Serrana. 2016. Disponível em: <http://g1.globo.com/rj/ regiao-serrana/noticia/2016/01/mariotricano-assume-prefeitura-de-teresopolisno-rj.html>.

SCARINI, J.; RODRIGUES, B. Tragédia na Serra do Rio completa 5 anos e ainda há espera por ajuda. G1 Região Serrana. 2016. Disponível em: <http://g1.globo.com/rj/ regiao-serrana/noticia/2016/01/tragediana-serra-do-rio-completa-5-anos-e-ainda-haespera-por-ajuda.html>.

SERAFIM, E.; QUELHAS, O. L. G. Governança corporativa - contribuições de boas práticas para o desempenho das organizações. In: 4th International Conference On Industrial Engineering and Industrial Management, San Sebastian, Espanha, 8-10 set. 2010. p. 140-150. Disponível em: <https://www. researchgate.net/publication/266524269_ Governanca_Corporativa_-_Contribuicoes_ de_Boas_Praticas_para_o_Desempenho_das_ Organizacoes $>$.

TATAGIBA, L. Os conselhos gestores e a democratização das políticas públicas no Brasil. In: DAGNINO, Evelina (Org.). Sociedade civil e espaços públicos no Brasil. São Paulo: Paz e Terra, 2002. p. 47-103. 
TAVARES, J. B. Conselhos de gestão de políticas públicas: de espaços de constituição de esfera pública não estatal à formação de um sistema nacional de representação. 2006. 203 p. Dissertação (Mestrado em Administração) Universidade Federal de Lavras, Lavras, 2014. Disponível em: <http:/ / repositorio.ufla.br/ jspui/handle/1/2367>.

TRIBUNAL DE CONTAS DA UNIÃO (TCU). Referencial básico de governança aplicável a órgãos e entidades da administração pública. Versão 2. Brasília: TCU, Secretaria de Planejamento, Governança e Gestão, 2014. Disponível em? <http://portal.tcu.gov.br/lumis/portal/file / fileDownload.jsp?inline=1\&fileId=8A8182A 24F0A728E014F0B34D331418D>. Acesso em: 10 mar. 2016.
VIANA, N. Estado, democracia e cidadania: a dinâmica da política institucional no capitalismo. Rio de Janeiro: Achiamé, 2003. Disponível em: <http:// movaut. net/wp-content/uploads/2012/09/ EstadoDemocraciaeCidadaniaNildoViana2. pdf>. Acesso em: 10 fev. 2015.

WALZER, M. The civil society argument. In: BEINER, R. (Ed.). Theorising citizenship. Albany: State University of New York Press, 1995. p. 231-55.

WOLFE, M.; STIFFEL, M.A voice of the excluded - popular participation in development: utopia or necessity? London: Unrisd / Zen Books, 1994.

\section{Sobre os autores:}

Michelle Muniz Bronstein: Doutoranda em Administração pelo PPGA da Unigranrio. Mestre em Comunicação Social pela PUC-Rio. Especialista em Gestão da Cultura pela UNESA. Administradora -FACCE/UNIFESO. E-mail: mmichellebronstein@hotmail.com

Joaquim Rubens Fontes Filho: Doutor em Administração - EBAPE/FGV. Mestre em Engenharia de Produção - COPPE/UFRJ. Mestre em Administração Pública - EBAP/ FGV. MBA em Controladoria - FIPECAFI/USP. Engenheiro de Produção - UFRJ. E-mail: Joaquim.rubens@fgv.br

Gabriel Alves Pimenta: Mestre em Administração - EBAPE/FGV. Graduado em Relações Internacionais pela PUC-Rio. E-mail: gabrielpimenta@protonmail.com 